\title{
Editorial
}

\section{Nutrition of infants and young children}

The journal is receiving many papers on childhood nutrition. The editorial board has therefore decided to dedicate a number of issues of the journal to research on children's nutritional health, interventions in children, and policy implications. This issue is especially targeting research on children of pre-school age or younger.

The first paper involves monitoring and surveillance from the perspective of child growth ${ }^{(1)}$. It is a very important paper, pointing at the large number of countries that have adopted the new growth standards based on breast-fed children.

Assessment is dealt with in papers related to physical activity $^{(2)}$, possession score $v$. poverty index ${ }^{(3)}$ and a nutrition knowledge questionnaire ${ }^{(4)}$. Breast-feeding is of course an important part of this issue, looking at links between breast-feeding and adiposity ${ }^{(5)}$ and the father's role in breast-feeding support ${ }^{(6)}$.

The very hot topic of cognition and nutrition is dealt with in two papers ${ }^{(7,8)}$. Childhood nutrition of course includes issues of undernutrition ${ }^{(9,10)}$, stunting ${ }^{(11)}$, general growth ${ }^{(12)}$ and nutrient status ${ }^{(13,14)}$. Among the interventions, the interested reader can find a folic acid intervention during pregnancy ${ }^{(8)}$ and a nutrition and physical activity intervention in 2-4-year-olds ${ }^{(15)}$. Effects of a change in foods approved by the Special Supplemental Nutrition Program for Women, Infants and Children (WIC) on food sales are described $^{(16)}$, and last but not least, an important paper on the targeting of children in marketing of foods ${ }^{(17)}$ is included in this issue. We wish you a good time reading this issue; and trust that you will find good use for the included papers and perhaps of the complete issue in teaching or in your own research.

\section{Agneta Yngve Editor-in-Chief \\ Marilyn Tseng Irja Haapala Allison Hodge Deputy Editors}

\section{References}

1. de Onis M, Onyango A, Borghi E et al. (2012) Worldwide implementation of the WHO Child Growth Standards. Public Health Nutr 15, 1603-1610.

2. Bayer O, Jarczok M, Fischer J et al. (2012) Validation and extension of a simple questionnaire to assess physical activity in pre-school children. Public Health Nutr $\mathbf{1 5}$ 1611-1619.

3. Rohner F, Tschannen AB, Northrop-Clewes C et al. (2012) Comparison of a possession score and a poverty index in predicting anaemia and undernutrition in pre-school children and women of reproductive age in rural and urban Cote d'Ivoire. Public Health Nutr 15, 1620-1629.

4. Vereecken C, De Pauw A, Van Cauwenbergh S et al. (2012) Development and test-retest reliability of a nutrition knowledge questionnaire for primary-school children. Public Health Nutr 15, 1630-1638.

5. Gopinath B, Subramanian I, Flood VM et al. (2012) Relationship between breast-feeding and adiposity in infants and pre-school children. Public Health Nutr 15 , $1639-1644$.

6. Nickerson LE, Sykes AC \& Fung TT (2012) Mothers' experience of fathers' support for breast-feeding. Public Health Nutr 15, 1780-1787.

7. McAfee AJ, Mulhern MS, McSorley EM et al. (2012) Intakes and adequacy of potentially important nutrients for cognitive development among 5-year-old children in the Seychelles Child Development and Nutrition Study. Public Health Nutr 15, 1670-1677.

8. Chatzi L, Papadopoulou E, Koutra K et al. (2012) Effect of high doses of folic acid supplementation in early pregnancy on child neurodevelopment at 18 months of age: the mother-child cohort 'Rhea' study in Crete, Greece. Public Health Nutr 15, 1728-1736.

9. Zongrone A, Winskell K \& Menon P (2012) Infant and young child feeding practices and child undernutrition in Bangladesh: insights from nationally representative data. Public Health Nutr 15, 1697-1704.

10. Masibo PK \& Makoka D (2012) Trends and determinants of undernutrition among young Kenyan children: Kenya Demographic and Health Survey; 1993, 1998, 2003 and 2008-2009. Public Health Nutr 15, 1715-1727.

11. Fenn B, Bulti AT, Nduna T et al. (2012) An evaluation of an operations research project to reduce childhood stunting in a food-insecure area in Ethiopia. Public Health Nutr 15, 1746-1754.

12. Thakwalakwa CM, Ashorn P, Jawati M et al. (2012) An effectiveness trial showed lipid-based nutrient supplementation but not corn-soya blend offered a modest benefit in weight gain among 6- to 18-month-old underweight children in rural Malawi. Public Health Nutr 15, $1755-1762$.

13. Abdul-Razzak KK, Khoursheed AM, Altawalbeh SM et al. (2012) $\mathrm{Hb}$ level in relation to vitamin D status in healthy infants and toddlers. Public Health Nutr 15, 1683-1687.

14. Hotz C, Chileshe J, Siamusantu W et al. (2012) Vitamin A intake and infection are associated with plasma retinol among pre-school children in rural Zambia. Public Health Nutr 15, 1688-1696.

15. De Coen V, De Bourdeaudhuij I, Vereecken C et al. (2012) Effects of a 2-year healthy eating and physical activity intervention for 3-6-year-olds in communities of high and low socio-economic status: the POP (Prevention of Overweight among Pre-school and school children) project. Public Health Nutr 15, 1737-1745. 
16. Ayala GX, Laska MN, Zenk SN et al. (2012) Stocking characteristics and perceived increases in sales among small food store managers/owners associated with the introduction of new food products approved by the Special Supplemental Nutrition Program for Women, Infants, and Children. Public Health Nutr 15, 1771-1779.
17. Mehta K, Phillips C, Ward P et al. (2012) Marketing foods to children through product packaging: prolific, unhealthy and misleading. Public Health Nutr 15, 1763-1770. 